\title{
¿El financiamiento público de las artes es relevante?
}

\author{
Ana Beatriz Díaz Conty Colunga
}

\begin{abstract}
Resumen
El financiamiento público de las artes es un tema ampliamente discutido, quizás aún más en sociedades con economías de mercado. En este artículo se presentan perspectivas distintas sobre lo que conlleva financiar las artes con recursos gubernamentales. Primero, desde un enfoque que justifica la eficiencia y la necesidad de un equilibrio de mercado óptimo y socialmente deseable respecto a la producción de arte. Y, después, desde un enfoque centrado en el contenido de las obras y la importancia de asegurar que éstas realmente existan, papel que le correspondería a las instancias gubernamentales. Finalmente, se puede concluir que ambas perspectivas apuntan hacia la misma dirección: la de asegurar la difusión social del arte. Así, ambos enfoques podrían presentarse en debates sobre la asignación del presupuesto gubernamental a la cultura y las artes.
\end{abstract}

Palabras clave: financiamiento público, subsidio, demanda, arte crítico, economía terciarizada.

\section{DOES PUBLIC FINANCING OF THE ARTS MATTER?}

\begin{abstract}
Public financing of the arts is a greatly discussed topic, maybe, even more in market economies. This article presents different perspectives about what it takes to finance the arts with public resources. Firstly, from an approach that justifies efficiency and the need of a sociably desirable and optimum market equilibrium with respect to art production. Secondly, from an approach that is centered in the content of the artworks and the importance of reassuring that these contents indeed exist, role that would correspond to government institutions. Finally, we can conclude that both perspectives aim to the same direction: reassuring art's social dissemination. Consequently, both approaches are complementary or could be addressed in that way, especially in debates for budget allocation for the arts and culture.
\end{abstract}

Keywords: public financing, subsidy, demand, critical art, tertiary economy.

Dol: http://doi.org/10.22201/codeic.16076079e.2019.v20n4.a7 


\section{Ana Beatriz Diaz Conty Colunga}

Licenciada en Economía por el Instituto Tecnológico de Monterrey. Actualmente cursa la maestría en Artes con enfoque en investigación en el Centro de Investigación y Posgrado de la Facultad de Artes Visuales de la Universidad Autónoma de Nuevo León.

\section{Introducción}

Aunque quizá bastante dialogado, discutido, defendido o polemizado, el otorgar recursos públicos a las artes es una realidad que prevalece aún en territorios con diversos e innovadores esquemas de financiamiento. Incluso en sociedades mayormente capitalistas la intervención gubernamental para regular algún mercado o proveer algún bien o servicio es necesaria. Hay algunas áreas de intervención bastante claras como la educación, la salud o el transporte, en las que son pocos los debates sobre si se debe o no financiar, aunque el sector privado está cada vez más involucrado.

Y ¿por qué no son tan debatidos los apoyos gubernamentales en dichos sectores? Porque generalmente a la producción o al consumo de los bienes o servicios en estos sectores se les pueden asociar beneficios sociales a mediano o corto plazo. Por ejemplo, la educación forma individuos con una mayor productividad y participación, lo que tiene efectos positivos en la comunidad en general y la hace socialmente deseable. Sin embargo, este valor social no necesariamente se refleja en el indicador de precio que los consumidores están dispuestos a pagar ni el que los productores necesitarían para ofrecer la educación en mayor cantidad. A esto se le llama externalidades positivas que pueden darse a través del consumo o de la producción. El precio de equilibrio, al cual se llega según la oferta y la demanda, no termina por incentivar a los productores a ofrecer más o a los consumidores a consumir más, pero debido a que existen externalidades positivas se justifica el financiamiento público para que haya más cantidad del bien o servicio y con esto se beneficie a toda la sociedad.

A las artes también se les asocian externalidades positivas en su consumo y producción que quizás no están tan claramente difundidas. Éstas se abordarán posteriormente y se utilizará éste y otros conceptos para justificar el apoyo público. Y, aunque en la mayoría de los presupuestos gubernamentales se asignan un rubro para la cultura y las artes, también se sufre de grandes recortes. Sería interesante abordar en otra investigación los recortes presupuestales al sector cultural y estudiar su comportamiento al compararlos con otros rubros del presupuesto gubernamental. 
El objetivo de este escrito es argumentar en favor del financiamiento público a la cultura y las artes desde la economía de mercado; así como complementar dicha justificación con una visión de la importancia del financiamiento público desde los estudios culturales.

\section{Definición del bien cultural y las industrias culturales}

¿Qué estudian los economistas cuando hablan de arte? Para el análisis económico del arte, Rascón (2009) afirma que "Un economista no dice ni pretende definir qué es arte". Es decir, no se intenta definir el arte en términos estéticos, sino que la economía lo define en términos del bien cultural para poder analizar su comportamiento e importancia social.

Por su parte, los bienes (o servicios) culturales los define Throsby (2001) como aquellos que: "[...] involucran la creatividad en su producción, incorporan hasta cierto punto la propiedad intelectual y transmiten significados simbólicos". Se puede hacer la distinción entre los bienes culturales y los bienes ordinarios debido a que los primeros tienen otras características que permiten o, más bien, necesitan un análisis diferenciado.

¿Pero por qué es necesario definir también a las industrias culturales? La aclaración es pertinente debido que desde esa perspectiva el argumento del autofinanciamiento es mucho más factible y puede contraponerse al del financiamiento público. Throsby (2001) propone que las industrias culturales están centradas en las ideas creativas. A partir de éstas, las industrias se perfilan hacia afuera, a medida que sobrevienen otras contribuciones para generar una mayor y más amplia gama de productos. La unión del arte y la cultura, o el bien cultural, está al centro de estas industrias y forma parte del estudio de las industrias culturales. Sin embargo, hay muchas más actividades que les permiten ser lucrativas por sí mismas en el mercado y en las que los artistas o el arte por sí solo no caben o no tienen posibilidad de participar bajo las mismas condiciones.

Es importante precisar la diferencia entre el bien cultural y las industrias culturales debido a que también existen iniciativas de apoyo y de fomento para estas últimas. Sin embargo, en este escrito no nos referiremos precisamente a ellas, ya que son mucho más amplias y abarcan más actividades que la artística. En este sentido, la unEsco define las industrias culturales como:

Aquellos sectores de actividad organizada que tienen como objeto principal la producción o la reproducción, la promoción, la difusión y/o la comercialización de bienes, servicios y actividades de contenido cultural, artístico o patrimonial.

También establece que las industrias culturales vinculan el arte y la cultura con dimensiones concretas como la economía, el mercado y la propiedad intelectual. Los bienes culturales son parte y centro de las industrias culturales, pero cuando se habla de ellas no necesariamente se hace referencia a los bienes culturales. 


\section{¿Por qué se otorga presupuesto a las artes según los economistas?}

Partiendo de un argumento económico, el apoyo a las artes debe ser justificado como cualquier intervención a otra industria o bien. Heilbrun y Grey (2001) explican las razones válidas para ello en el contexto de una economía de libre mercado - aquella que se basa en mercados competitivosy la óptima distribución de los recursos-, mencionan que una intervención gubernamental sólo debe suceder cuando existan imperfecciones en el mercado o cuando la distribución del ingreso no sea óptima, y esto conlleve a que la cantidad demandada de cierto bien sea menor a la cantidad socialmente satisfactoria. ¿Sucede algo de esto en el mercado de las artes que justifique su financiamiento público? Para explicar la intervención gubernamental en el financiamiento a las artes hay que entender primero por qué la producción y consumo de arte sería menor a la óptima.

Efectivamente, es posible asociar imperfecciones de mercado al consumo y producción de arte. Throsby (2001) menciona dentro de ellas a las externalidades positivas asociadas a las artes y el arte como bien público. Las externalidades positivas son una imperfección del mercado ya que el consumidor individual no percibe o identifica los beneficios colectivos de su consumo o producción para el resto de la sociedad. Heilbrun y Grey (2001) definen las externalidades como los efectos que "existen cuando la actividad de un agente económico afecta a otros agentes en maneras por las que no se recibe ninguna compensación". Es decir, hay efectos asociados al consumo o producción de ciertos bienes que no se ven reflejados en su precio. Y estos efectos pueden ser negativos o positivos. Por ejemplo, una externalidad negativa podría ser la contaminación al producir determinado producto; sin embargo, dicho bien no se encarece por ese efecto que como sociedad sí tiene un costo. O, al contrario, el consumo del transporte público produce externalidades positivas como reducir el tráfico, por lo tanto, es socialmente deseable que más personas lo utilicen; no obstante, su precio de equilibrio no refleja esta externalidad positiva y quizá no sea lo suficientemente bajo para incentivar una mayor demanda del bien a la cantidad conveniente a la sociedad.

El arte es uno de estos bienes que producen externalidades positivas, por lo tanto, hay una demanda social, ya que es de interés público que exista una mayor cantidad, de la que el mercado produce sin ninguna intervención, de ese bien cultural. Consecuentemente, la demanda total de los bienes artísticos deberá ser la sumatoria de las demandas individuales y la demanda social. Se sabe que, en la ley de oferta y demanda, a una mayor cantidad demandada, mayor es el precio que el productor puede cobrar por el bien en cuestión. El diferencial entre lo que el individuo está dispuesto a pagar y el precio, para que el productor ofrezca la cantidad socialmente deseable, es la cantidad del subsidio, un tipo de financiamiento público. El apoyo gubernamental en forma 
Imagen 1. Una persona o cien pueden escuchar un mismo concierto con el mismo resultado, esto es el principio de la no rivalidad. de subsidio es una compensación por dicho diferencial para incentivar a los productores a producir una mayor cantidad de arte, y a los consumidores de consumirla.

Y ¿qué externalidades positivas son las que se le atribuyen al arte para justificar esa intervención? Entre las que mencionan Heilbrun y Grey (2001) se encuentran la contribución del arte a la identidad de un territorio; la formación de un legado a generaciones futuras que permita conocer cómo se pensaba y vivía, para cuestionar el antes y el ahora; beneficios a la economía local mediante la atracción de consumidores no residentes; y el fomento a la innovación y experimentación mediante la creación.

Otra de las llamadas imperfecciones en el mercado asociadas a las artes que menciona Throsby (2001) es que el arte, o al menos cierto tipo, tiene características de un bien público. ¿Qué quiere decir esto? Que posee dos peculiaridades: la primera es la no rivalidad, que significa que alguien puede consumirlo sin afectar que otros lo consuman de igual manera. Una pintura o una pieza de música no se agota al verla o escucharla por muchas personas, respectivamente. La segunda es la no exclusividad, es decir, que no hay manera de prohibir que cualquier persona disfrute o se beneficie del arte (ver imagen 1).

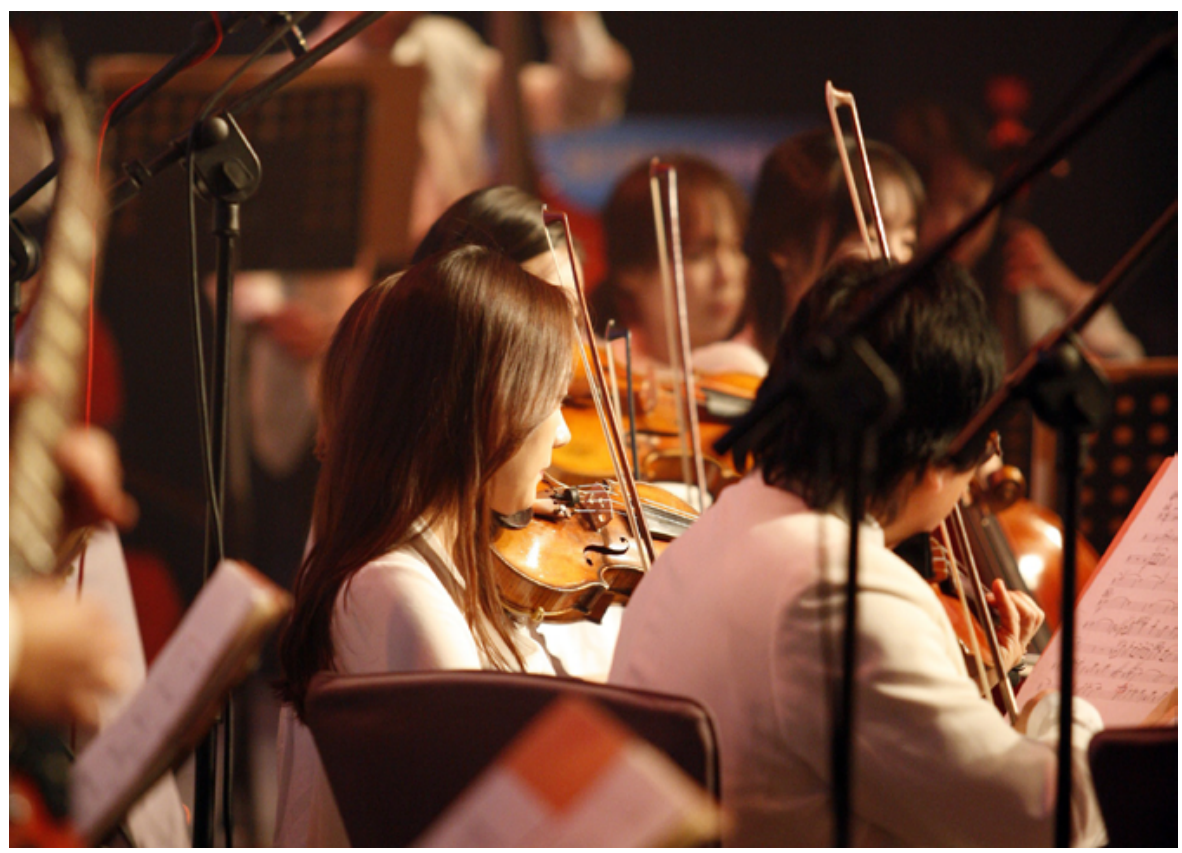

La información imperfecta o la falta de información es otra imperfección del mercado que justifica la intervención. "Las artes pueden funcionar como un 'gusto adquirido', significando que el consumidor tiene que estar familiarizado con ellas para disfrutarlas, y que una vez que los consumidores tienen este conocimiento, es probable que su demanda de arte incremente notablemente" (Heilbrun y Grey, 2001: 237). Sin un acceso inicial, los individuos no podrán experimentar el placer 
o los beneficios de consumir arte. Este acceso puede ser "negado" por recursos o falta de información. Pierre Bourdieu en "Elementos de una teoría sociológica de la percepción artística" también hace referencia a cómo la familiarización y exposición del individuo con obras de arte es lo que favorece su entendimiento. Así, se puede hablar de que el arte tiene beneficios marginales crecientes a diferencia de otros bienes ordinarios. Esto se refiere a que no hay saciedad y, a medida que más se consume, más aumenta su necesidad y utilidad. Este principio económico de los beneficios marginales crecientes se puede relacionar con lo que Bourdieu menciona como la capacidad de "descifrar" la obra de arte y el aumento de los medios para dicha decodificación a medida que el individuo se habitúa y se expone de manera continua a él. Entonces, el financiamiento público a las artes tiene también un argumento de equidad, el de garantizar el acceso a todos los individuos con el fin de no limitar los beneficios potenciales del consumo de arte.

Existe un contraargumento al subsidio de las artes: la idea de que aquellos que más la consumen comúnmente pertenecen a los grupos más enriquecidos en una sociedad determinada. Para debatir esto, es necesario que la política cultural esté rotundamente dirigida: "Debemos reconocer que los subsidios a las artes pueden tener resultados perversos en cualquier país, a menos que el sistema tributario sea justamente progresivo o la asistencia a los artistas incluya un gran número de programas claramente dirigidos al beneficio de la población de bajo ingreso" (Heilbrun y Grey, 2001). Además, dicho juicio también se puede contrastar con la teoría de los estudios culturales, que definen el arte con una visión más amplia. Plantean que no se limita a un determinado grupo de poder y sus propias formas de legitimización. De esta manera Ana María Guasch explica en "Los estudios visuales. Un estado de la cuestión" (2003) el propósito de reivindicar obras que anteriormente habían sido excluidas por un canon definido por determinados valores estéticos. Así, incorporando estas nociones de cultura y arte, el financiamiento público tendría objetivos de acceso, equidad e inclusión.

\section{¿Cómo intervienen las instancias gubernamentales en el financiamiento a las artes?}

Rascón (2009) explica el apoyo a las artes con recursos públicos debido a la naturaleza del bien cultural: "En términos económicos, el mercado funcionaría eficientemente si todo artista financiara su arte por completo, pero para ello los consumidores deberían consumir y pagar precios de equilibrio, los cuales serían más altos de los que suelen pagar en la realidad, debido a los factores de tiempo, riesgo y naturaleza mixta del bien cultural". ¿Y cómo intervienen las instancias gubernamentales? Rascón responde que con tres formas: la regulación y las condiciones institucionales, el apoyo financiero indirecto y las subvenciones directas. En la regulación y condiciones institucionales menciona principalmente la creación de incentivos para la producción y consumo por 
Imagen 2. Es imperativo garantizar el acceso para cumplir con los objetivos de eficiencia.

Artista: Ernesto Neto, Obra: GaiaMotherTree, Fotografía: art_inthecity. medio de la legislación. El apoyo financiero indirecto es aquel que se logra de la reducción de costos donde caerían dentro de este rubro la exención de impuestos a donadores, por ejemplo. Y en las subvenciones directas sí se otorga una transferencia directa de capital al artista.

Aunque Heilbrun y Grey se pueden utilizar para entender el porqué del apoyo gubernamental; con Rascón se puede ampliar el concepto, entendiendo dos clasificaciones de financiamiento y la de la regulación. Y también atribuye a la naturaleza del bien la justificante de esta intervención, además de los factores de tiempo y riesgo que conlleva la actividad artística.

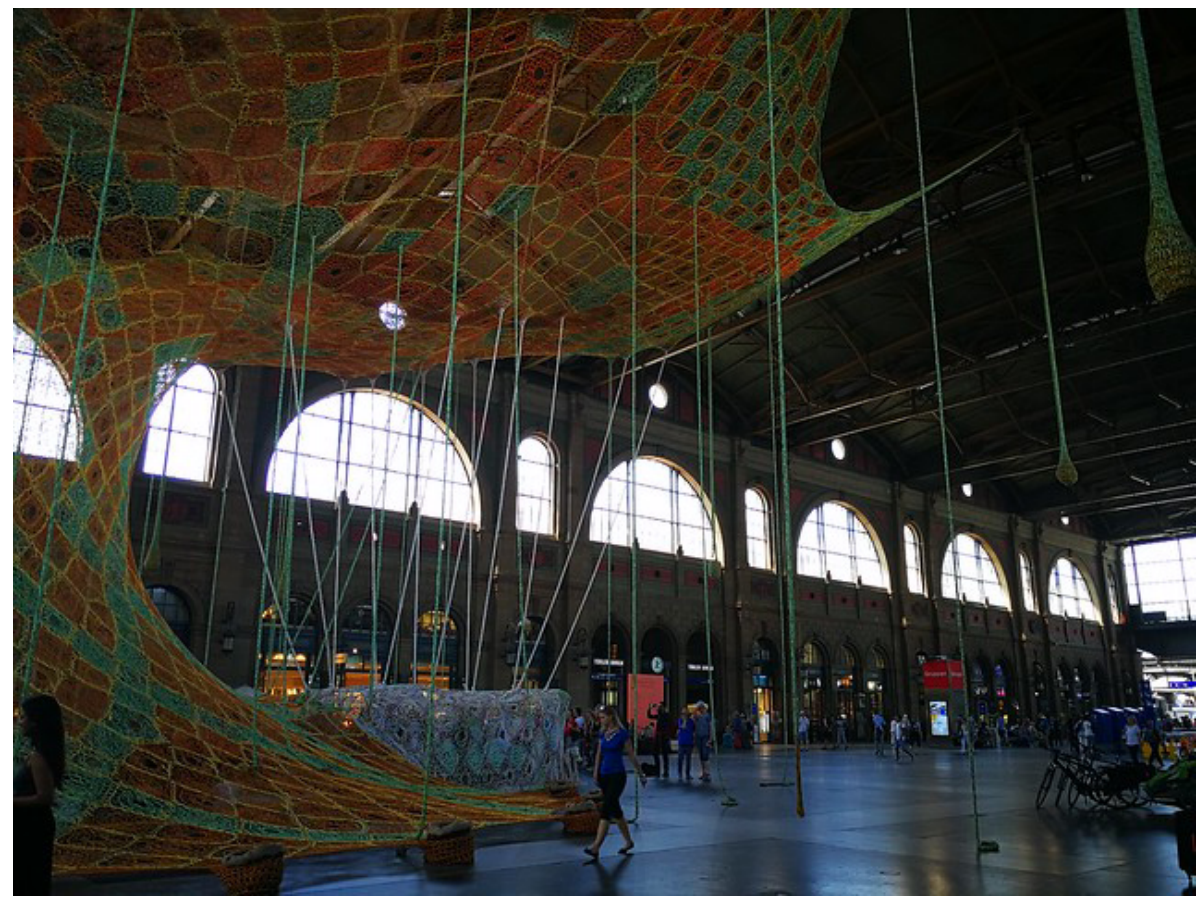

Como se menciona, los mecanismos de financiamiento pueden ser diversos. Sin embargo, es pertinente su evaluación, no sólo para determinar si se cumple con el principio de eficiencia, sino para designar los incentivos correctos que permitan alcanzar otros objetivos antes mencionados como el acceso.

\section{Una visión no economicista de la pertinencia del financiamiento público de las artes}

Con lo expuesto anteriormente se entiende el porqué del financiamiento público de las artes, sin embargo, la teoría económica expuesta no menciona qué arte se pretende financiar. Se entiende por arte a un consenso o las artes en sus tradicionales disciplinas. No obstante, en el contexto actual, y sobre todo con la introducción de los estudios culturales, que permiten otras visiones de la cultura, se amplía el concepto y a su vez la diversidad de formas y tipos de manifestaciones artísticas. 
En un contexto de globalización y con el crecimiento de la economía terciarizada, donde predominan bienes de naturaleza intangible, el arte y la creatividad están tomando un papel preponderante, y es aquí donde también se desarrollan las industrias culturales. Nelly Richard (2007) en "Estudios Visuales, políticas de la mirada y la crítica de imágenes" habla sobre la necesidad de un arte crítico, de no hacer las distinciones tradicionales de arte alto y caer en clasificaciones elitistas, sino de poder distinguir entre las obras que se construyen con simplicidad de significado y decodificación, en ocasiones con el propósito de insertarse en un mercado, o el de la espectacularización; versus aquellos que producen significados, conocimiento y conflicto. Asimismo, Guerra Miranda (2015) habla del arte como una herramienta de discursos críticos y reflexivos que permite no sólo exponer a las sociedades contemporáneas, sino también construir y forjar acuerdos.

Entonces, en esta situación de predominio de la economía terciarizada con nuevos roles y reglas, ¿cuál es el papel del financiamiento público o el de las instituciones públicas en el arte? Ana María Guasch (2003), haciendo referencia a Rosalind Krauss y Hal Foster, menciona cómo la obra de arte se convierte en un tipo de resistencia ante la mercantilización. Es por esto que el apoyo público es necesario e importante, de lo contrario muchos contenidos desaparecerían en el libre mercado.

En este orden de ideas, J. Luis Brea propone que "La función de las instituciones públicas respecto a las nuevas prácticas, con vistas a garantizar su inscripción en lo público, será más bien la de promover u optimizar en entornos protegidos la circulación social de aquellos contenidos que el libre mercado de las industrias culturales desestimaría en su regulación interesada por la ley de la audiencia" (2004). También propone que las instituciones públicas aseguren que los contenidos se difundan, que lleguen, y así, que existan. Que aquellos contenidos que se definan dentro de un arte crítico, como lo propone Richard, y que en una economía de mercado no tendrían garantizada su existencia, cuenten con, podríamos decir, apoyos públicos.

\section{Conclusiones}

Es una realidad que conforme las instituciones culturales y artistas independientes se enfrentan con mayor frecuencia a los recortes presupuestales han encontrado alternativas de financiamiento que son cada vez más importantes en su actividad. Sin embargo, el objetivo de este escrito es resaltar que aun cuando es necesario que la cultura y las artes diversifiquen sus financiamientos, las subvenciones públicas son relevantes debido a fines sociales. La distribución social del arte debe garantizarse para todos, así como la circulación de contenidos que aporten beneficios y externalidades positivas, y que, muchas veces, podrían ser los que los mecanismos del libre mercado rechazarían. 
Entender la importancia del financiamiento público de la cultura y las artes, y por qué éste es eficiente y necesario desde una perspectiva económica y social, es vital para justificar su prioridad en un presupuesto público o, en su caso, para incentivar a la iniciativa privada a formar parte, sin dejar de garantizar los objetivos sociales, a pesar de que la naturaleza del apoyo privado debe analizarse por sí misma.

\section{Referencias}

* Bourdieu, Pierre (1970). Elementos de una teoría sociológica de la percepción artística. En Sociología del Arte. Buenos Aires: Ediciones Nueva Visión.

* Brea, J. Luis (2004). APÉNDICE. Redefinición de las prácticas artísticas. En El Tercer Umbral. Murcia, España: CENDEAC.

* Guasch, A. (2003). Los Estudios Visuales. Un Estado de la Cuestión. Estudios Visuales, 1, 8-16.

* Guerra, L. R. (2015). Democracy \& Art, The New World Academy and the Out-OfPlace Space of the Inexistent. Revista De Estudios Globales Y Arte Contemporáneo, 3(1), 413-432.

* Heilbrun, J. y Gray, C. (2001). The Economics of Art and Culture (2 edición). Nueva York, Estados Unidos de América: Cambridge University Press.

* Rascón, Cristina (2009). La Economía del Arte. México, D.F.: Nostra Ediciones.

* Richard, Nelly (2007) Estudios visuales, políticas de la mirada y crítica de las imágenes. En Fracturas de la Memoria. México; FCE.

* Throsby, David (2001). Economics and Culture. Cambridge: Cambridge University Press.

\section{Cómo citar este artículo}

* Díaz Conty Colunga, Ana Beatriz (2019). ¿El financiamiento público de las artes es relevante? Revista Digital Universitaria (RDU). Vol. 20, núm. 4 julio-agosto. Dol: http:// doi.org/10.22201/codeic.16076079e.2019.v20n4.a7.

Recepción: 08/09/2016 Aprobación: 15/05/2019. 